\title{
Contribuição ao zoneamento bioclimático brasileiro: reflexões sobre o semiárido nordestino
}

Contribution to the Brazilian bioclimatic zoning: considerations about the tropical semi-arid climate

\section{Tathiane Agra de Lemos Martins \\ Leonardo Salazar Bittencourt Cláudia Mariz de Lyra Barroso Krause}

\section{Resumo}

Tathiane Agra de Lemos Martins Programa de Pós-graduação em Arquitetura, Faculdade de Arquitetura e Urbanismo Universidade Federal do Rio de J aneiro Rua dos Ipês, s/ n, Prédio da Reitoria, sala 433, Cidade Universitária

Rio de J aneiro - RJ - Brasil CEP 21941-901 Tel.: (21) 2598-1661 E-mail: tathianemartins@gmail.com

Leonardo Salazar Bittencourt Centro de Tecnologia, Departamento de Arquitetura e Urbanismo Universidade Federal de Alagoas Campus A. C. Simões, BR 104 Norte, KM 97, Cidade Universitária Maceió - Al - Brasil CEP 57072-970 Tel.: (82) 3214-1290 E-mail: Isb54@hotmail.com

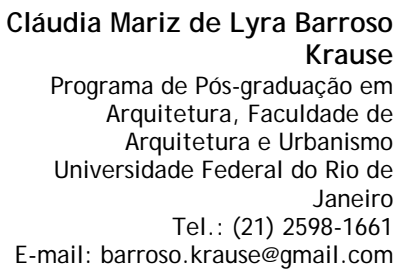

Recebido em 30/09/11

Aceito em 29/03/12

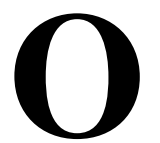

Zoneamento Bioclimático Brasileiro faz parte da NBR 15220-3, em vigor desde 2005. Consiste na divisão do território brasileiro em 8 zonas climáticas. Para cada zona são feitas recomendações de estratégias de condicionamento térmico passivo para habitações de interesse social. Este trabalho tem como objetivo examinar o referido zoneamento quanto à adequabilidade de suas diretrizes para as cidades localizadas no semiárido alagoano. Por meio de simulação computacional, comparou-se o desempenho de uma edificação padrão, implantada na cidade de Maceió (quente-úmido), com o desempenho da mesma edificação na cidade de Pão de Açúcar (semiárido). As duas edificações foram modeladas de acordo com as diretrizes construtivas recomendadas pela NBR 15220-3, considerando a zona 8. De forma análoga, comparou-se o desempenho térmico da mesma edificação ajustada às recomendações para a zona 7. Uma análise das características do clima de Pão de Açúcar demonstra a existência de dois períodos diferentes (8 meses secos e 4 meses chuvosos), que demandam estratégias bioclimáticas diferenciadas. Concluise pela necessidade de aperfeiçoamento nos critérios da classificação dos municípios situados no semiárido alagoano, bem como da criação de subzonas que contemplem as particularidades climáticas regionais.

Palavras-chave: Zoneamento bioclimático. Eficiência energética. Clima tropical semiárido.

\section{Abstract}

The Bioclimatic Zoning of Brazil is part of the Standard NBR 15220-3 ${ }^{a}$ in force since 2005. It consists in the division of the Brazilian territory into 8 climatic zones. For each zone, it recommends specific building design guidelines for passive thermal conditioning for low-cost housing. This paper examines the Brazilian Bioclimatic Zoning regarding the suitability of its design guidelines for the cities of the semi-arid region of the state of Alagoas. Computer simulations were performed to compare the thermal performance of a case-study building, located in the city of Maceió (hot-humid) with the performance of the same building located in Pão de Açúcar (semi-arid). The building was modeled according to the design guidelines of the NBR 15220-3 concerning the recommendations for zone 7 and zone 8 . An analysis of the climate characteristics of the town of Pão de Açúcar demonstrates the existence of two different periods (8 months of drought and 4 months of rain), requiring different bioclimatic strategies. The study concluded that it is necessary to improve the criteria of classification of the cities in the semi-arid, as well as to establish sub-zones, covering the particularities of the region's climate.

Keywords: Bioclimatic zoning. Energy efficiency. Brazilian tropical semi-arid.. 


\section{Introdução}

Diante do atual estágio político-energético mundial, tornou-se indispensável pensar o projeto de arquitetura com respostas construtivas adequadas às características climáticas do sítio. Adotar essa postura, desde a fase inicial de concepção da edificação, contribui para que o edifício seja mais confortável e eficiente do ponto de vista energético.

No Brasil, existe atualmente uma importante demanda por soluções arquitetônicas que contemplem tais preocupações no âmbito das habitações de interesse social, onde os usuários dependem, fundamentalmente, de meios passivos para a obtenção de conforto térmico. No entanto, para que diretrizes de projeto possam ser orientadas com vistas a torná-las mais adequadas ao clima, é necessário que os arquitetos e urbanistas conheçam as características do clima onde a obra será construída. O mapeamento e o cadastramento sistemático dessas estratégias facilitam o entendimento e proporcionam a adoção de práticas mais comprometidas com a qualidade ambiental dos espaços projetados.

O território brasileiro, em virtude de sua larga extensão, abrange uma ampla diversidade climática e muitas particularidades regionais. Tal fato evidencia a necessidade de identificação dessa diversidade e agrupamento em zonas bioclimáticas, para que possam ser formuladas diretrizes construtivas adequadas para cada uma dessas zonas (RORIZ; GHISI; LAMBERTS, 2001).

\section{Zoneamento bioclimático no Brasil}

A elaboração de um mapeamento bioclimático para o Brasil vem sendo desenvolvida desde a década de 80 por diferentes instituições de pesquisa. O Instituto de Pesquisas Tecnológicas de São Paulo (IPT), em 1985, desenvolveu metodologia com o objetivo de avaliar o desempenho de habitações unifamiliares térreas, estabelecendo requisitos e critérios de desempenho para os componentes das edificações em situações de inverno e de verão. Foi definido um zoneamento climático de verão, com 11 zonas, e um zoneamento climático de inverno, com 9 zonas (MADEIRA, 1999). Silva (1994), a partir do uso das normais climatológicas de 204 estações meteorológicas brasileiras, estabelece um zoneamento bioclimático em função dos desvios da zona de conforto proposta por Givoni (1992). Tal zoneamento foi composto de 3 grandes zonas e suas respectivas subzonas, representando um total de 13 zonas bioclimáticas para fins de edificações.
Em 1997, institutos de pesquisas dentro do contexto do Programa Brasileiro de Construção Habitacional elaboraram critérios mínimos de desempenho para habitações térreas de interesse social. $\mathrm{O}$ documento apresenta 8 zonas bioclimáticas, abrangendo, para cada uma delas, critérios para verão e inverno. No ano seguinte, no contexto do Projeto de Inovação Tecnológica, Roriz, Lamberts e Ghisi (1998) propuseram um zoneamento bioclimático para fins de estudo do conforto térmico em habitações de interesse social, resultando em 8 zonas bioclimáticas.

Em 2003, é apresentado o primeiro zoneamento bioclimático de caráter normativo para o Brasil, como parte da NBR 15220-3 (ABNT, 2005), que entra em vigor em 2005. O atual zoneamento consiste na divisão do território brasileiro em 8 zonas bioclimáticas, para as quais são apresentadas recomendações de diretrizes construtivas e detalhamento de estratégias de condicionamento térmico passivo para habitações de interesse social.

A metodologia utilizada na definição do atual zoneamento bioclimático brasileiro baseia-se nos desvios da zona de conforto adaptada do diagrama psicrométrico proposto por Givoni (1992). Para a classificação das cidades brasileiras, foram utilizados dados das normais climatológicas divulgadas pelo INMET para 330 cidades, as quais foram utilizadas, também, para estimar, através de interpolação, o clima das demais cidades.

Inicialmente, o território brasileiro foi dividido em 6.500 células, estas caracterizadas pela posição geográfica e pelas variáveis climáticas referentes às médias mensais de temperatura, máxima e mínima, e médias mensais de umidade relativa do ar, das quais, para apenas 330 células, contou-se com os dados das Normais Climatológicas medidos de 1961 a 1990 em 206 cidades; e com dados das Normais Climatológicas e outras fontes medidos de 1931 a 1960 em 124 cidades (ABNT, 2005).

Os pontos referentes a cada uma das variáveis climáticas mencionadas foram plotados no diagrama psicrométrico adaptado de Givoni (1992), definindo-se, assim, uma reta por mês. As estratégias bioclimáticas são definidas pelo cálculo do percentual do comprimento da reta mensal encontrada sobre cada uma das estratégias indicadas no diagrama. O conjunto das estratégias obtidas ao longo de um ano climático de referência para cada localidade foi comparado com os critérios de classificação definidos pela norma (Anexo B da NBR 15220-3 (ABNT, 2005)) definindo sua zona bioclimática (ZB). Num 
segundo momento, o documento propõe a formulação de diretrizes construtivas para cada uma das 8 Zonas Bioclimáticas, para o estabelecimento das estratégias de condicionamento térmico passivo. Para isso, foram considerados no documento parâmetros e condições de contorno relativos ao tamanho das aberturas para ventilação, à proteção das aberturas, às vedações externas (tipo de parede externa e tipo de cobertura) e às estratégias de condicionamento térmico passivo (ABNT, 2005).

O uso de médias mensais, no entanto, pode produzir distorções, sobretudo em regiões que apresentem amplitudes anuais e sazonais importantes, a exemplo da região climática do semiárido brasileiro. Além disso, a ausência de estações de monitoramento, em muitos dos municípios brasileiros, impede uma maior precisão nos resultados de interpolação. Segundo Roriz (1999), menos de $4 \%$ dos mais de 5.500 municípios brasileiros possuem dados climáticos publicados.

Alguns trabalhos têm sido recentemente desenvolvidos com a finalidade de preencher algumas dessas lacunas, identificando-se também limitações na norma.

Zárate et al. (2008) trabalharam para aperfeiçoar os processos de interpolação de dados climáticos para fins de classificação bioclimática no estado de Minas Gerais. Os autores calibraram uma rede neural artificial com dados climáticos de médias mensais, coordenadas geográficas e, também, a altitude de cada ponto da rede de 66 estações meteorológicas, interpolando dados para 1.709 localidades do estado.

Pereira e Assis (2005a, 2005b) apontaram discrepâncias entre as recomendações normativas e o desempenho térmico passivo de edificações em Belo Horizonte, principalmente com relação às características das envoltórias.

Outros estudos também avaliaram a norma brasileira no que se refere à aplicabilidade de sua classificação bioclimática. Bastos, Krause e Beck (2007) e Rocha, Assis e Gonçalves (2009) elaboraram um mapeamento demonstrando o potencial eólico regional para uso da ventilação natural. Os autores discutiram a inadequação quanto à aplicação efetiva da ventilação natural como estratégia bioclimática recomendada pela norma, ante a indisponibilidade desse recurso em determinadas regiões brasileiras.

\section{Zoneamento bioclimático para 0 semiárido nordestino}

Nimer (1979) classifica o Nordeste brasileiro como uma das climatologias mais complexas do mundo, devido à irregularidade espacial e temporal na distribuição das chuvas. Como consequência desse fenômeno, é possível encontrar na região Nordeste do Brasil mesorregiões geográficas muito particulares, cujos climas vão do superúmido, característico das zonas litorâneas, até o clima seco, quase desértico do sertão ${ }^{1}$, conhecido como o semiárido nordestino (NIMER, 1979).

O clima tropical semiárido brasileiro caracterizase, predominantemente, pela ocorrência de amplitudes significativas de temperatura do ar tanto diária como sazonal, e de grandes massas de ar quentes, carregadas de poeira. Esse clima, também denominado "quente-seco", apresenta duas estações bem distintas: um longo período de seca e um curto período de chuva, radiação direta intensa e baixo teor de umidade relativa do ar (ROMERO, 1988).

O estado de Alagoas possui três mesorregiões geográficas com características climáticas bem definidas, sendo $43 \%$ de seu território situado na mesorregião do semiárido. De acordo com o Zoneamento, apenas 8 cidades alagoanas foram classificadas a partir das normais climatológicas divulgadas pelo INMET. Destas, 7 estão localizadas na Zona Bioclimática 8 (clima quente e úmido). Entre elas, cidades situadas no litoral de clima quente e úmido, mas também municípios situados na mesorregião do semiárido, com até 8 meses secos, como é o caso da cidade de Pão de Açúcar (identificada como número 7 na Figura 1). Apenas a cidade de Água Branca (identificada como número 8 no mesmo mapa) foi classificada na Zona Bioclimática 5.

A partir das 8 cidades do Estado classificadas com base em dados medidos, foi estabelecido 0 zoneamento das demais por interpolação, ficando o atual zoneamento bioclimático de Alagoas como mostra a Figura 2, abaixo.

Este trabalho tem como objetivo verificar a adequabilidade das estratégias contidas no zoneamento bioclimático brasileiro para cidade localizada no semiárido alagoano.

\footnotetext{
${ }^{1} 0$ Nordeste está dividido em 4 mesorregiões geográficas: Zona

da Mata (litoral), Agreste, Sertão e Meio Norte. O termo

"Sertão" é utilizado para designar a região que possui clima tropical semiárido.
} 


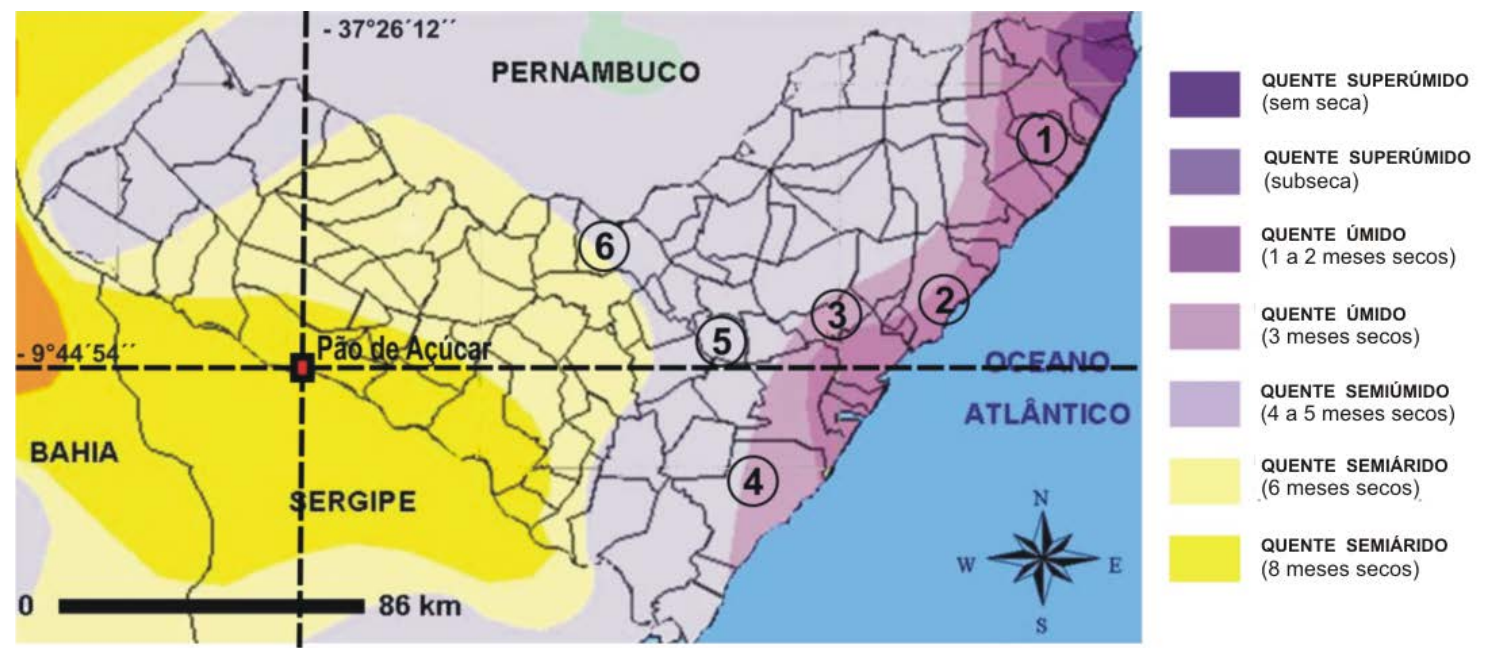

Figura 1 - Mapa de climas para o estado de Alagoas

Fonte: adaptado IBGE (2011).

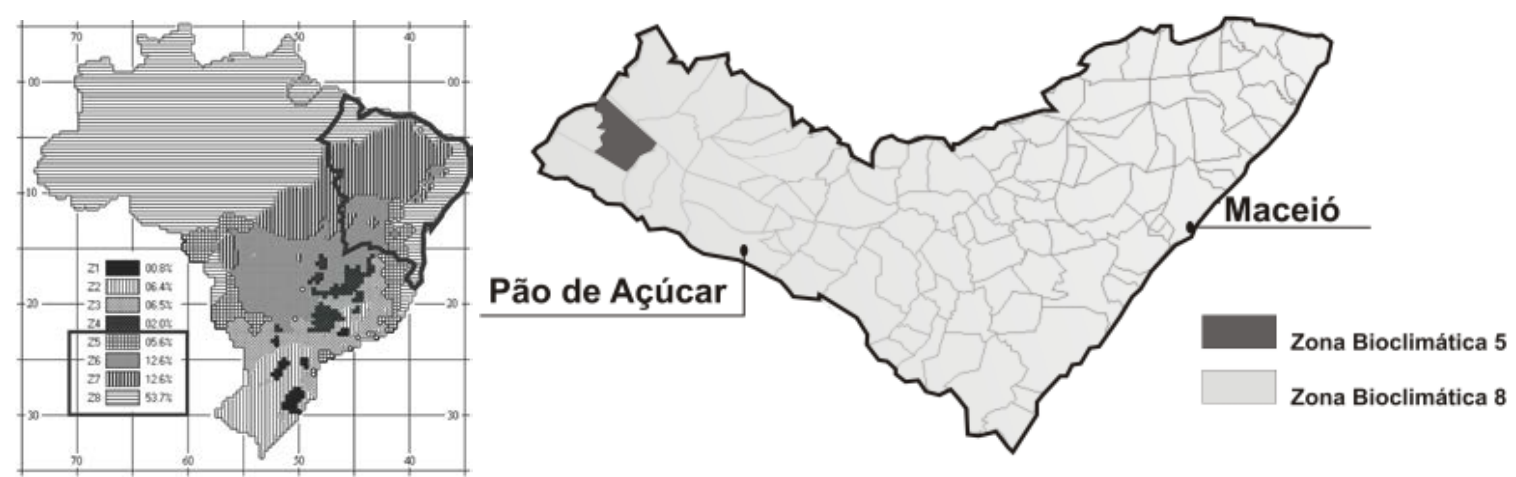

Figura 2 - Zoneamento Bioclimático Brasileiro, com destaque para o estado de Alagoas

Fonte: ABNT (2005).

\section{Método}

Para atender ao objetivo proposto, foi adotada uma metodologia composta de três etapas:

(a) análise climática comparativa entre os dados de três municípios, sendo dois deles localizados na ZB-8 (Maceió e Pão Açúcar) e um localizado na ZB-7 (Petrolina), com a finalidade de demonstrar as diferenças existentes entre as características climáticas das três cidades;

(b) análise bioclimática sazonal dos dados meteorológicos levantados das três cidades, realizada com base no diagrama psicrométrico, para identificação das estratégias bioclimáticas mais adequadas para cada caso; e

(c) realização de simulações computacionais para avaliação do desempenho térmico de edificações que adotem diretrizes construtivas recomendadas pela NBR 15220-3, considerando o condicionamento térmico passivo de uma habitação popular. Os modelos computacionais foram avaliados comparando-se o desempenho térmico deles para as três cidades mencionadas.

\section{Análise comparativa}

Entre os métodos clássicos de investigação científica, lançou-se mão da abordagem hipotéticodedutiva e do procedimento comparativo para a realização da primeira etapa metodológica do trabalho. O método comparativo consiste no confronto de elementos, levando-se em conta seus atributos, com a finalidade de verificar semelhanças e de explicar divergências que possam ser constatadas, bem como verificar a existência de relações entre os elementos comparados (MARCONI; LAKATOS, 2000).

Foram examinados os dados climáticos do município de Pão de Açúcar e os dados climáticos de dois municípios, sendo um situado na ZB-7 e o outro na ZB-8. Devido à dificuldade de obtenção de dados para a região em estudo, o primeiro critério para seleção foi a disponibilidade deles 
para as três cidades. Primeiramente, foi selecionado um município localizado na mesma ZB na qual a zona de Pão de Açúcar está localizada. Nesse caso, optou-se por trabalhar com os dados para a cidade de Maceió. Petrolina foi selecionada pelo fato de que nenhum município do semiárido alagoano, mesmo apresentando indicadores climáticos semelhantes aos de Petrolina, foi classificado na ZB-7 (Figura 3).

Para a realização das duas etapas metodológicas principais do trabalho, foram obtidos dados climáticos horários para as três cidades. Para a cidade de Maceió, os arquivos climáticos foram os disponibilizados pelo Laboratório de Eficiência Energética de Edificações (LabEEE - UFSC). No entanto, para Petrolina e Pão de Açúcar, devido à ausência desses arquivos finalizados, foram utilizadas séries de três horários, fornecidas pelo INMET (de 1997 a 2007 para Pão de Açúcar, e de 2007 a 2010 para Petrolina). Esses dados foram tratados com o auxílio do programa Meteonorm 6.1. O referido programa possui modelos que permitem a reconstituição de dados incompletos e a extrapolação de dados horários a partir de dados estatísticos para determinada localidade. No caso da indisponibilidade de dados estatísticos, o programa interpola a partir de estações situadas nas proximidades, considerando além das coordenadas geográficas, a altitude e as características mais relevantes do sítio geográfico. A descrição completa dos modelos nos quais estão baseados os cálculos do programa supracitado, bem como a validação destes podem ser encontradas em Remund, Kunz e Schilter (2007). Meteonorm exporta dados em diversos tipos de formato usuais (e.g. TMY, EPW, TRY, etc.) e definidos pelo usuário. Neste trabalho, o programa também foi utilizado para gerar arquivos, a partir dos mesmos dados climáticos, em formato TRY e EPW.

Os dados climáticos das três cidades foram inseridos no programa AnalysisBio para conhecimento das principais estratégias de condicionamento ambiental. Com o objetivo de melhor entender as características do clima, a partir das estratégias recomendadas pelo diagrama psicrométrico sugerido por Givoni (1992), os dados foram analisados anual e sazonalmente, a fim de identificar a magnitude de eventuais variações.

\section{Avaliação computacional}

Num segundo momento, uma habitação popular de referência foi modelada conforme as diretrizes construtivas recomendadas pela NBR 15220-3 (ABNT, 2005), considerando a ZB-7 e a ZB-8. A fim de conhecer o comportamento dos dois modelos de habitação gerados conforme recomendações da norma brasileira, buscou-se identificar e comparar a resposta em desempenho térmico dessas recomendações para cada cidade, observando-se, ainda, o rigor climático sazonal destas para um mesmo edifício.

A avaliação obedeceu a duas etapas principais:

(a) definição de um modelo computacional de referência de habitação popular para integração dos parâmetros construtivos relativos a cada uma das duas zonas investigadas (ZB-7 e ZB-8); e

(b) avaliação do desempenho térmico das habitações de referência quando localizadas no clima de Pão de Açúcar, Maceió e Petrolina, com o auxílio do programa EnergyPlus² versão 6.0.0. Para a análise dos resultados obtidos, foi calculado o número de graus-hora para resfriamento (GHR) para cada caso.

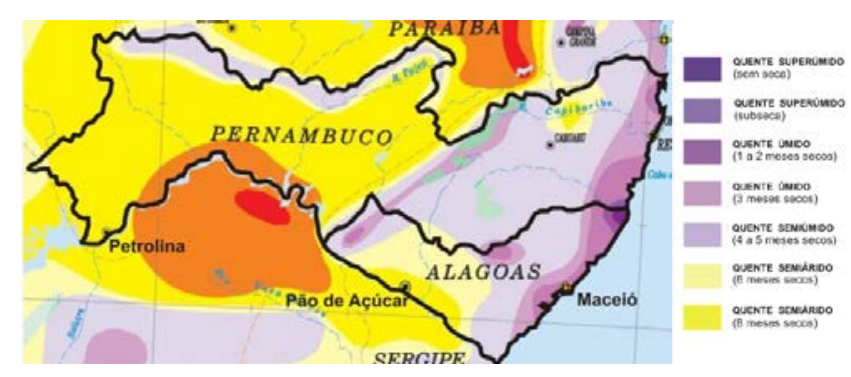

Figura 3 - Cidades selecionadas para o estudo, destacando Petrolina e Pão de Açúcar com a mesma classificação climática do IBGE - quente e seco com até 8 meses secos

Fonte: IBGE (2011). ${ }^{2}$

\footnotetext{
${ }^{2}$ O programa EnergyPlus, assim como o atual zoneamento bioclimático brasileiro, foi utilizado como base para elaboração da metodologia de avaliação no Regulamento Técnico de Qualidade (RTQ-R).
} 


\section{Definição da habitação popular de referência}

Baseando-se nas informações oriundas de Pesquisas Nacionais de Amostras de Domicílio (IBGE, 2002) e Pesquisa de Sistema de Informações de Posses de Eletrodomésticos e Hábitos de Consumo (SISTEMA..., 1999), realizadas em 1997 e 2006 respectivamente, Tavares (2006) definiu protótipos habitacionais de acordo com a faixa de renda familiar. Entre os modelos definidos, foi selecionado para este trabalho o protótipo referente à habitação unifamiliar compatível à renda de até cinco salários mínimos nacionais.

O modelo de habitação popular selecionado possui área total de $63 \mathrm{~m}^{2}$, dividido em dois quartos, sala, banheiro e cozinha, com pé-direito de 2,8 m. O padrão de ocupação considerado, representando uma família composta de quatro habitantes, será detalhado mais adiante.

O referido modelo foi também selecionado como caso-base no trabalho de Matos (2007) sobre o desempenho térmico de habitações naturalmente ventiladas em Florianópolis e, posteriormente, empregado na metodologia do Regulamento Técnico de Qualidade para etiquetagem voluntária do nível de eficiência energética de edificações residenciais (RTQ-R).
Para a simulação de edificações, é necessária a definição de zonas térmicas do modelo. Assim, a referida residência foi modelada em quatro zonas térmicas, cada uma representando respectivamente os seguintes ambientes: quarto de casal, quarto de solteiro, sala e serviço (cozinha e banheiro). A zona escolhida para análise foi a sala (Figura 4).

\section{Parâmetros de simulação}

Os modelos da habitação foram simulados com o auxílio do programa computacional EnergyPlus, elaborado pelo Departamento de Energia dos Estados Unidos e destinado à avaliação de desempenho térmico-energético de edificações.

O programa apresenta diferentes tipos de algoritmos para a solução do balanço de calor e para o cálculo dos coeficientes de convecção do modelo. Neste trabalho, optou-se pela função de transferência de calor por condução (Conduction Transfer Function - CTF) e pelo método TARP para cálculo dos coeficientes de convecção, cálculos automáticos do programa. O algoritmo TARP utiliza coeficientes de convecção descritos pela ASHRAE (AMERICAN..., 1985) e pelas equações desenvolvidas por Walton (1983). Como foram considerados apenas ambientes com condicionamento passivo, apenas o coeficiente de convecção natural é calculado.

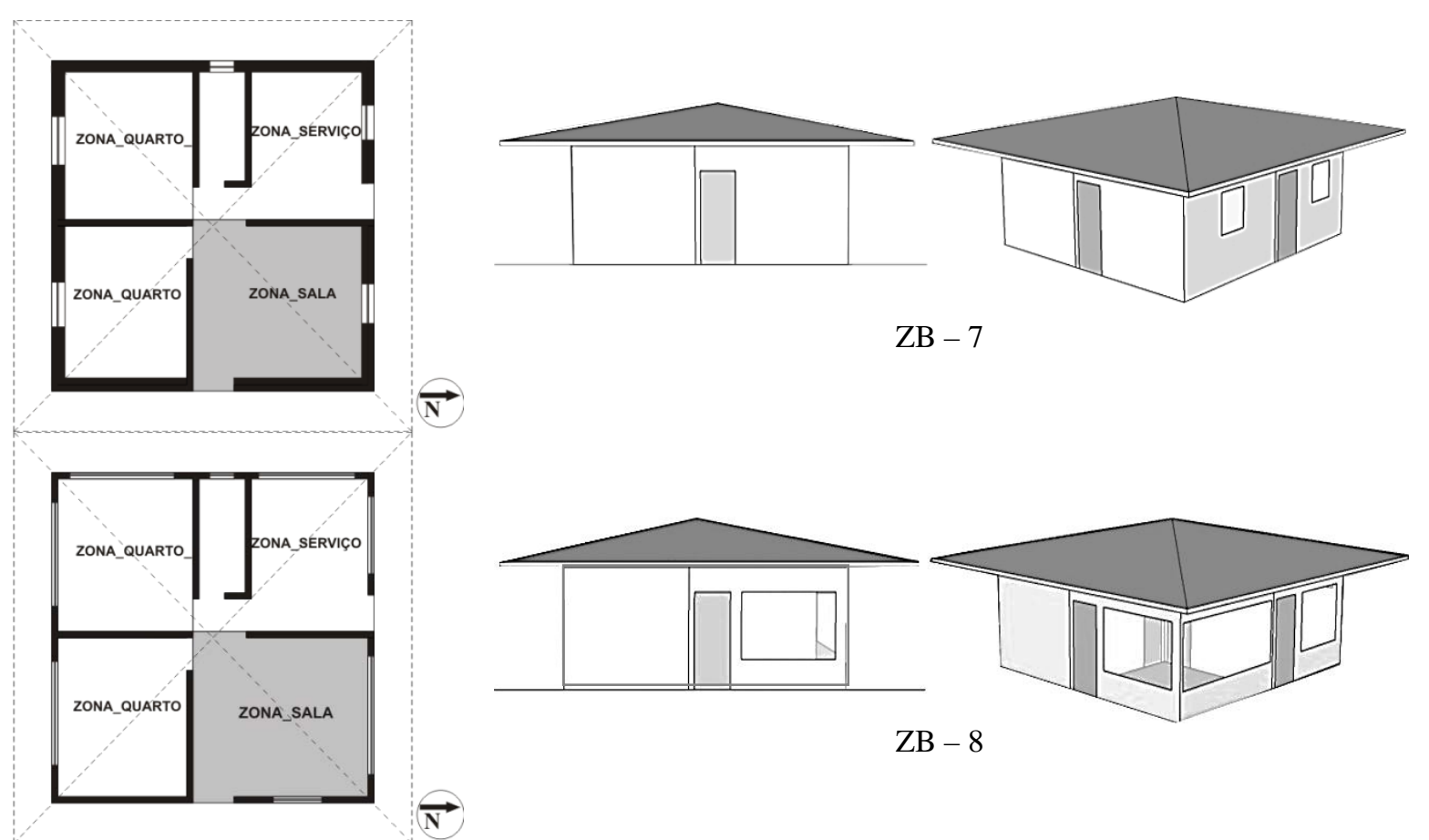

Figura 4 - Planta esquemática com as zonas térmicas consideradas no estudo de simulações, fachadas e perspectivas da habitação popular de referência para as duas zonas bioclimáticas investigadas 
Os parâmetros da envoltória considerados na avaliação foram os mesmos fixados pela NBR 15220-3 (ABNT, 2005):

(a) tamanho das aberturas para ventilação;

(b) proteção das aberturas; e

(c) vedações externas (tipo de parede e cobertura), para cada zona avaliada (ZB-7 e ZB-8).

Tais parâmetros foram variados conforme mostra a Tabela 1. As aberturas foram dimensionadas para $12 \%$ da área do piso (recomendação da norma para ZB-7) e para $50 \%$ da área do piso (referente à ZB8). Todas as janelas cadastradas foram compostas de vidro simples de $3 \mathrm{~mm}$ de espessura, sem proteções solares internas. De modo a contemplar o critério de sombreamento para as aberturas, recomendado pela ABNT para ambas as zonas bioclimáticas, foi considerado como máscara de sombra um ângulo de 30o, desejável para obter sombreamento das aberturas na latitude das três cidades.

O padrão de ocupação considerado para as habitações obedece a uma rotina diária de uso, das $18 \mathrm{~h}$ às $7 \mathrm{~h}$, pois durante o dia os usuários trabalham ou estudam. O sistema de iluminação artificial e um dos dois equipamentos considerados na rotina (televisão 14”, tubo) seguem a mesma agenda, enquanto o segundo equipamento definido (geladeira) apresenta rotina de uso contínuo. Os tempos médios de utilização dos equipamentos foram estimados com base na tabela de consumo do Procel (PROGRAMA..., 2011). Para a geladeira considerou-se uma potência média de $35 \mathrm{~W}$, e para a televisão (14”, tubo), 42 W. Adotou-se o valor 0,5 para a fração radiante de ganho de calor pelos equipamentos. Quanto aos ganhos em iluminação, nos dormitórios foram instalados $60 \mathrm{~W}$, e na cozinha e na sala, 100 W. A potência instalada no banheiro é de $40 \mathrm{~W}$. A densidade de potência média é de $5,7 \mathrm{~W} / \mathrm{m}^{2}$.

O programa Energyplus emprega o modelo de rede Airflow Network, validado para a simulação da ventilação natural (GU, 2007). Foi definida uma rotina que considera o uso contínuo da ventilação natural ao longo do ano para os dois modelos. Para a definição dos coeficientes de pressão nas fachadas foi utilizada a média dos coeficientes das superfícies delas (Surface Avarage Calculation, adequado apenas para modelos retangulares), com o auxílio da rotina de cálculo automático disponível no programa. Os dados para temperatura média mensal do solo foram processados pelo aplicativo Slab, associado ao EnergyPlus.

Tabela 1 - Características dos componentes utilizados na simulação correspondentes às duas alternativas examinadas

\begin{tabular}{|c|c|c|c|c|c|c|c|c|}
\hline \multirow{2}{*}{$\mathbf{Z B}$} & \multirow{2}{*}{\multicolumn{2}{|c|}{ Componentes Envoltória }} & & \multicolumn{5}{|c|}{ Parâmetros avaliação desempenho térmico ABNT } \\
\hline & & & $\mathbf{U}$ & $\mathbf{C}_{\mathbf{T}}$ & $\varphi$ & FS & A\% & \\
\hline \multirow{2}{*}{$\hat{N}$} & 营 & $\begin{array}{l}\text { Telha de barro }(1 \mathrm{~cm}) \\
\text { Colchão de ar } \\
\text { Laje de concreto }(20 \mathrm{~cm})\end{array}$ & 1,84 & 458 & 8 & 2,2 & \multirow{2}{*}{12} & \\
\hline & 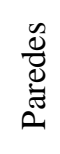 & $\begin{array}{l}\text { Tijolo } 6 \text { furos }(2 * 9 \text { x } 14 \text { x } 19 \\
\text { cm) } \\
\text { Argamassa assentamento }(1 \mathrm{~cm}) \\
\text { Argamassa emboço }(2,5 \mathrm{~cm})\end{array}$ & 1,21 & 312 & 8,6 & 1,4 & & \\
\hline \multirow{2}{*}{$\begin{array}{l}\infty \\
\dot{N}\end{array}$} & ن & $\begin{array}{l}\text { Telha de barro }(1 \mathrm{~cm}) \\
\text { Colchão de ar } \\
\text { Forro de madeira }(1 \mathrm{~cm})\end{array}$ & 2,00 & 32 & 1,3 & 2,4 & \multirow{2}{*}{50} & \\
\hline & 苞 & $\begin{array}{l}\text { Tijolo } 6 \text { furos }(9 \times 14 \text { x } 19 \mathrm{~cm}) \\
\text { Argamassa emboço }(2,5 \mathrm{~cm})\end{array}$ & 2,48 & 159 & 3,3 & 3,0 & & \\
\hline \multicolumn{9}{|c|}{ Fonte: ABNT (2005). } \\
\hline \multicolumn{9}{|c|}{ Nota: Legenda: } \\
\hline & \multicolumn{8}{|c|}{$\begin{array}{l}\text { U - Transmitância térmica }(\mathrm{W} / \mathrm{m} 2 . \mathrm{K}) \text {; } \\
\mathrm{CT} \text { - Capacidade Térmica ( } \mathrm{KJ} / \mathrm{m} 2 . \mathrm{K}) \text {; } \\
\varphi \text { - Atraso térmico (horas); }\end{array}$} \\
\hline
\end{tabular}


Com base na temperatura do ar interno, calcularam-se os somatórios de GHR para o período em análise (dia típico de verão e de inverno), para cada cidade. Esse indicador de análise de desempenho térmico, quando a primeira está acima da temperatura de base, consiste no somatório da diferença entre a temperatura operativa horária e a temperatura de base. Adotouse como temperatura-base a temperatura neutra de conforto ( $\left.\mathrm{T}_{\text {neutra }}\right)$, calculada de acordo com a equação proposta por De Dear e Brager (2002), em função da temperatura média externa $\left(\mathrm{T}_{\text {ext-média }}\right)$ (Equação 1).

$\mathrm{T}_{\text {neutra }}=0,31 * \mathrm{~T}_{\text {ext-média }}+17,8$

Eq.

1

Considerou-se ainda nesta análise uma tolerância térmica de adaptação, correspondente à satisfação de $80 \%$ dos usuários, relativa a uma aceitação de temperaturas até $3,5{ }^{\circ} \mathrm{C}$ acima ou abaixo da temperatura neutra (AMERICAN..., 2004).

\section{Resultados e discussões}

A seguir, são apresentados os dados climáticos levantados, acompanhados de sua avaliação bioclimática. As informações estão organizadas de modo a permitir que sejam observadas as características meteorológicas, assim como as respectivas estratégias bioclimáticas ao longo do ano, para cada uma das três cidades examinadas. Em seguida, são apresentados os resultados das simulações do desempenho térmico de um modelo de habitação popular quando implantada nas três cidades examinadas, mudando-se os valores das variáveis, conforme apresentado na Tabela 1.

\section{Análise bioclimática}

\section{Maceió (ZB-8)}

A cidade de Maceió encontra-se na mesorregião da Zona da Mata Atlântica, situada na costa litorânea nordestina. A capital alagoana está situada na latitude $9^{\circ} 40^{\prime}$ ao sul do Equador e na longitude $35^{\circ} 42^{\prime}$ oeste. O clima da cidade é caracterizado como quente e úmido, com radiação solar intensa e pequenas oscilações de temperatura, tanto diárias como sazonais. Possui temperatura média anual de $24,8{ }^{\circ} \mathrm{C}$ e variação anual de $2,8^{\circ} \mathrm{C}$ entre os valores médios mensais da temperatura do ar. As temperaturas médias mensais variam entre $22,9{ }^{\circ} \mathrm{C}$ e $27,9^{\circ} \mathrm{C}$ ao longo do ano.

Observa-se que a cidade de Maceió apresenta um elevado, e pouco oscilante, índice de umidade relativa do ar (durante dois terços do ano com umidade sempre superior a 90\%), o que contribui para que a temperatura ao longo do ano oscile muito pouco. Por ser uma cidade litorânea e estar sob a influência de grandes massas d’água, apresenta taxas de umidade relativa do ar com média de 78,3\%. A média pluviométrica anual da cidade é de 2.167,70 mm, porém apresenta importante variação anual quanto à distribuição de chuvas (BRASIL, 1992). Destacam-se duas estações:

(a) uma com altas temperaturas e pouca pluviosidade, com ocorrência de chuvas passageiras de setembro a fevereiro; e

(b) outra estação bastante chuvosa, apresentando elevada umidade e temperatura do ar mais baixa em relação à estação anterior e corresponde aos meses de abril a julho.

Os dados para um ano típico de Maceió são apresentados na Figura 5, abaixo.

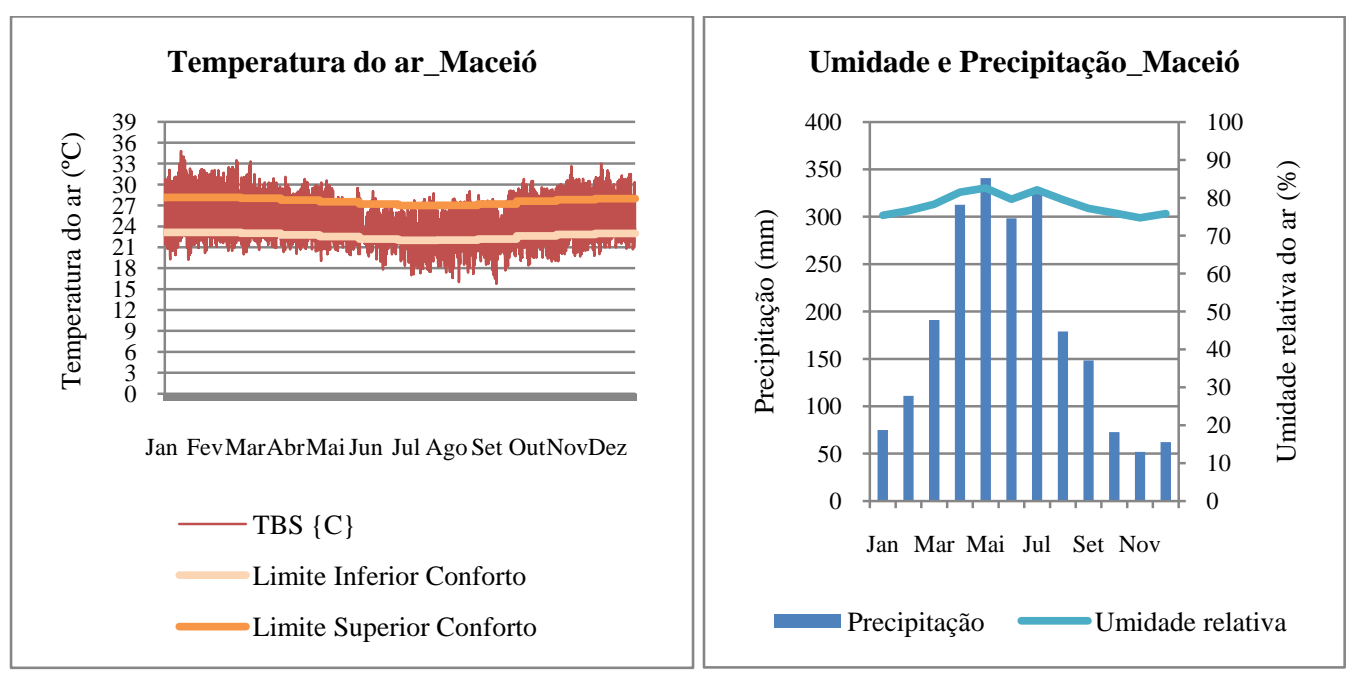

Figura 5 - Dados de temperatura do ar, umidade relativa e precipitação para a cidade de Maceió, AL 
Como consequência das variáveis climáticas que pouco oscilam ao longo dos meses, as orientações fornecidas pelo diagrama psicrométrico para Maceió apresentaram certa uniformidade durante todo o ano.

As estratégias recomendadas consistem no uso da ventilação associada ao sombreamento solar. Em $17 \%$ do tempo os dados encontram-se dentro da zona de conforto. Essa zona pode ser ampliada para 62,4 \% das horas do ano com o uso de ventilação. $O$ uso combinado de ventilação e inércia térmica produz uma ampliação de mais 13,7\% nas horas de conforto (Figura 6).

\section{Petrolina (ZB-7)}

A cidade de Petrolina está situada na mesorregião do sertão pernambucano (região do semiárido nordestino), na latitude $9^{\circ} 22^{\prime}$ sul e longitude $40^{\circ} 32^{\prime}$ oeste. O clima da cidade caracteriza-se por ser bastante quente ao longo do ano. O lugar apresenta importante amplitude térmica diária, de $12,3^{\circ} \mathrm{C}$ em média, e entre estações, uma amplitude de $4,6{ }^{\circ} \mathrm{C}$. A temperatura do ar, nos meses de verão, registra média das máximas de $33,5{ }^{\circ} \mathrm{C}$ e média das mínimas de $19^{\circ} \mathrm{C}$ (Figura 7).

Observa-se que a umidade média acompanha o índice pluviométrico baixo e concentrado da região. A média calculada para umidade atinge seu máximo no mês de março, com 68\%, e menor média em setembro, com $50 \%$. A precipitação pluviométrica média (dados das normais climatológicas) é de 609,8 mm anuais (BRASIL, 1992).

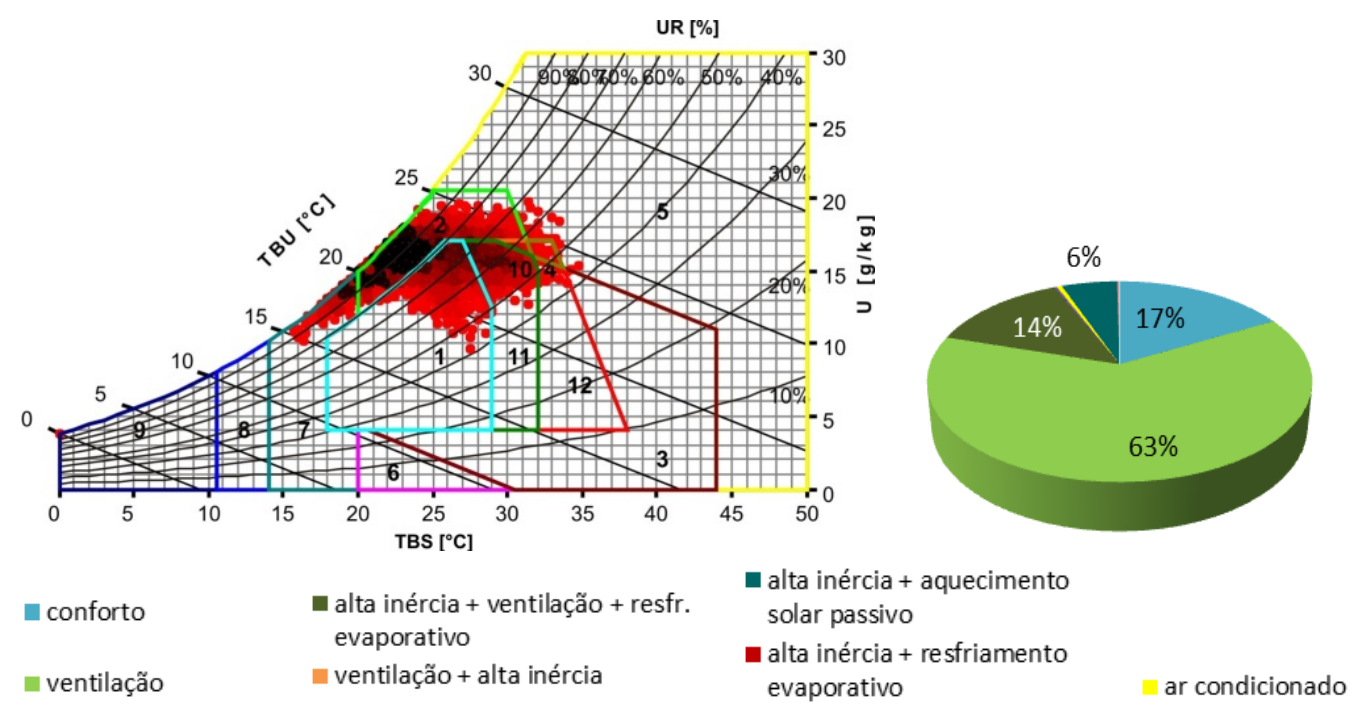

Figura 6 - Carta bioclimática para o município de Maceió (diagrama gerado pelo programa AnalysisBio)
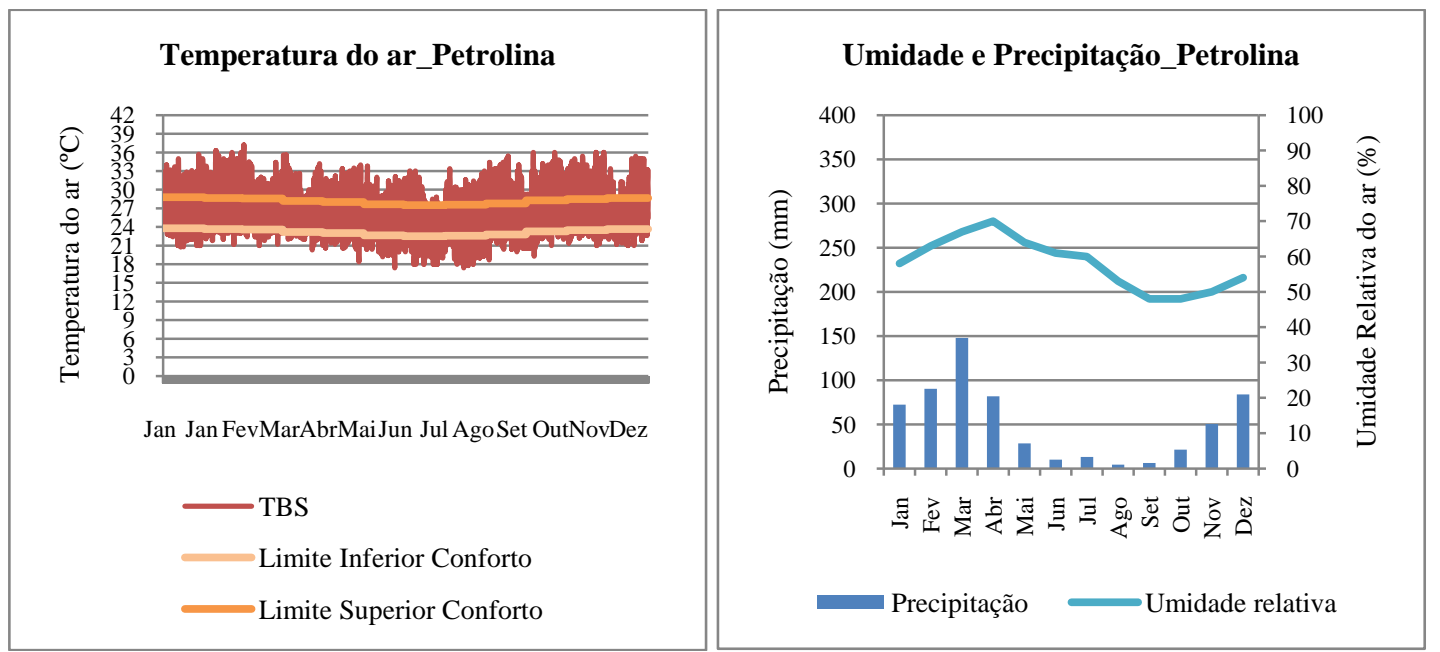

Figura 7 - Dados temperatura do ar, umidade relativa e precipitação para cidade de Petrolina-PE 
Diferentemente das características presentes em Maceió, Petrolina apresenta importantes oscilações nos valores da umidade relativa e da temperatura do ar de seus indicadores climáticos. Tal fato repercute na prescrição de estratégias bioclimáticas distintas para as duas estações do ano.

Para ampliar a zona de conforto (que corresponde a 53,9\% do tempo) nas edificações a serem projetadas na cidade de Petrolina, recomenda-se o uso da ventilação durante $12,9 \%$ do ano, esta associada ao resfriamento evaporativo e à alta inércia térmica para 21,9\% do ano (Figura 8). No entanto, uma característica importante a ser ressaltada diz respeito à sazonalidade dessas recomendações. Por exemplo, apesar de a estratégia da ventilação ser recomendada em cerca de $13 \%$ do ano, esta deve ser utilizada durante 4 meses, mesmo número de meses em que o ar condicionado também é recomendado, porém com menor expressão (1\%). Já o uso da alta inércia térmica associada ao resfriamento evaporativo aparece de forma mais uniforme como recomendação válida para o ano todo.

\section{Pão de Açúcar (ZB-8)}

Os dados coletados para Pão de Açúcar, AL (série histórica de 10 anos, 1997-2007), foram cedidos pela estação meteorológica do INMET situada na zona rural do município. No entanto, como a série disponibilizada apresentava dados para apenas três horários por dia, os referidos dados foram interpolados e reconstituídos para a criação de arquivo climático de referência (TRY) com o auxílio do programa Meteonorm 6.1.

Como já mencionado, uma das principais características do clima de localidades situadas na região semiárida, de clima quente e seco, é a significativa oscilação na temperatura ao longo do dia, com elevada temperatura durante o período diurno associada a baixas taxas de umidade relativa do ar. Em Pão de Açúcar, essa configuração é mais evidenciada nos períodos de outubro a abril. No período de maio a setembro, há uma significativa queda da média de temperatura (meses de inverno), apesar de a amplitude diária ainda ser razoável. Também neste período a umidade sofre significativo acréscimo, amenizando o rigor climático (Figura 9).

Conforme dados fornecidos pelo INMET (2008), a cidade de Pão de Açúcar apresenta uma temperatura média anual de $28,1{ }^{\circ} \mathrm{C}$ e uma amplitude anual de $11,02{ }^{\circ} \mathrm{C}$. O mês mais quente é dezembro, com temperatura média máxima de 36,5 ${ }^{\circ} \mathrm{C}$ e média mínima de $24{ }^{\circ} \mathrm{C}$ (oscilação diária média de $12{ }^{\circ} \mathrm{C}$ ). $\mathrm{O}$ mês menos quente é julho, com a média das máximas de $29,3{ }^{\circ} \mathrm{C}$ e média das mínimas de $20,7^{\circ} \mathrm{C}$. A amplitude térmica diária máxima registrada foi de $13,4{ }^{\circ} \mathrm{C}$, no mês de dezembro.

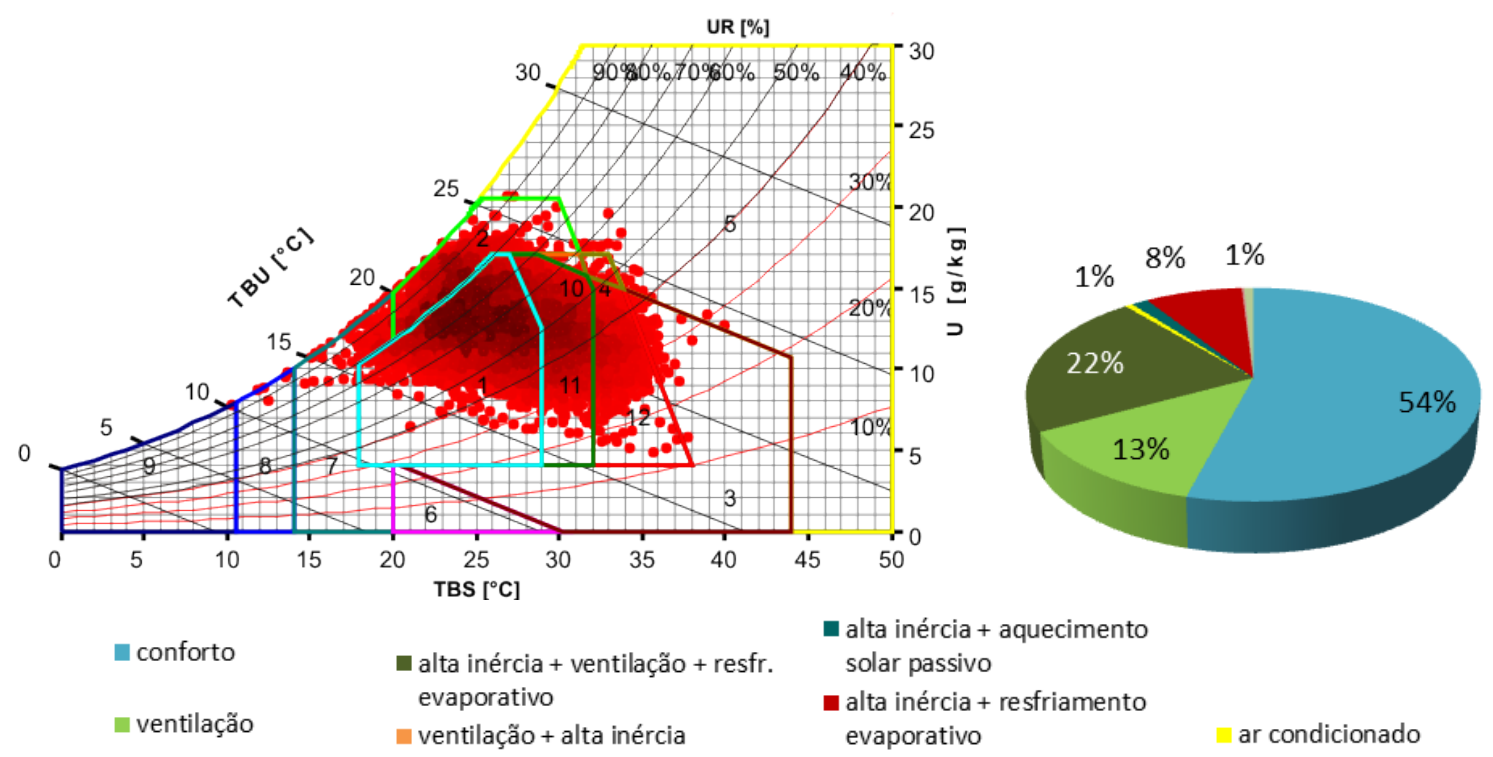

Figura 8 - Carta bioclimática para o município de Petrolina, PE 


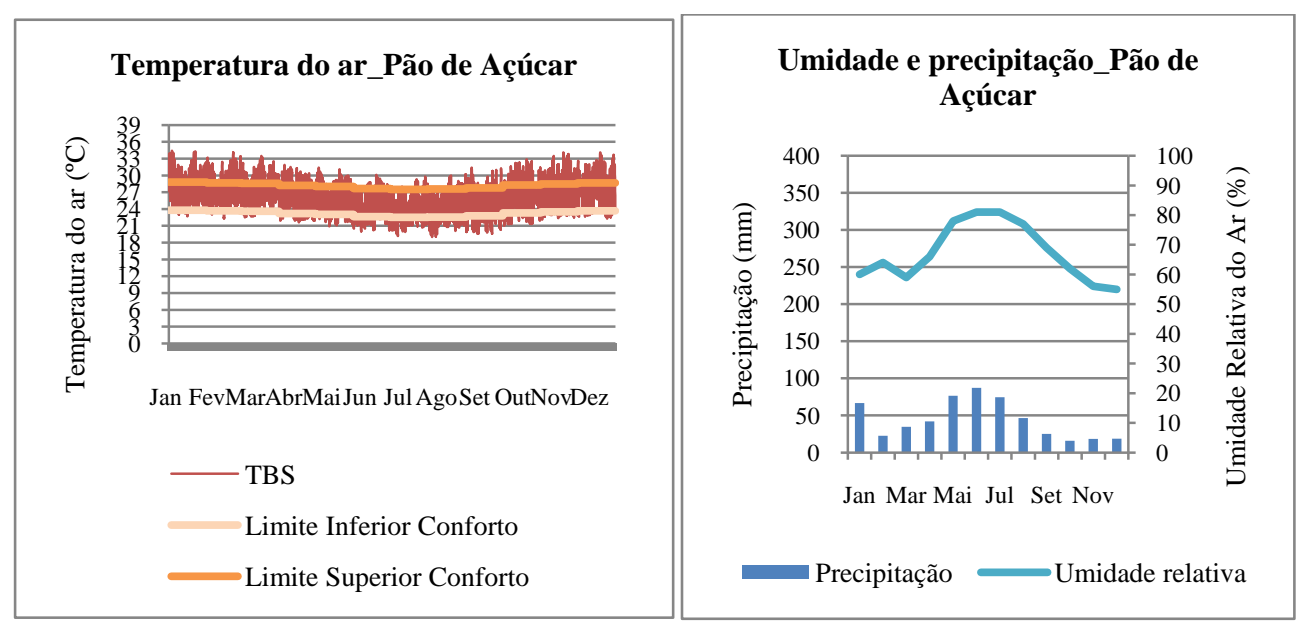

Figura 9 - Dados de temperatura do ar, umidade relativa e precipitação para cidade de Pão de Açúcar, AL

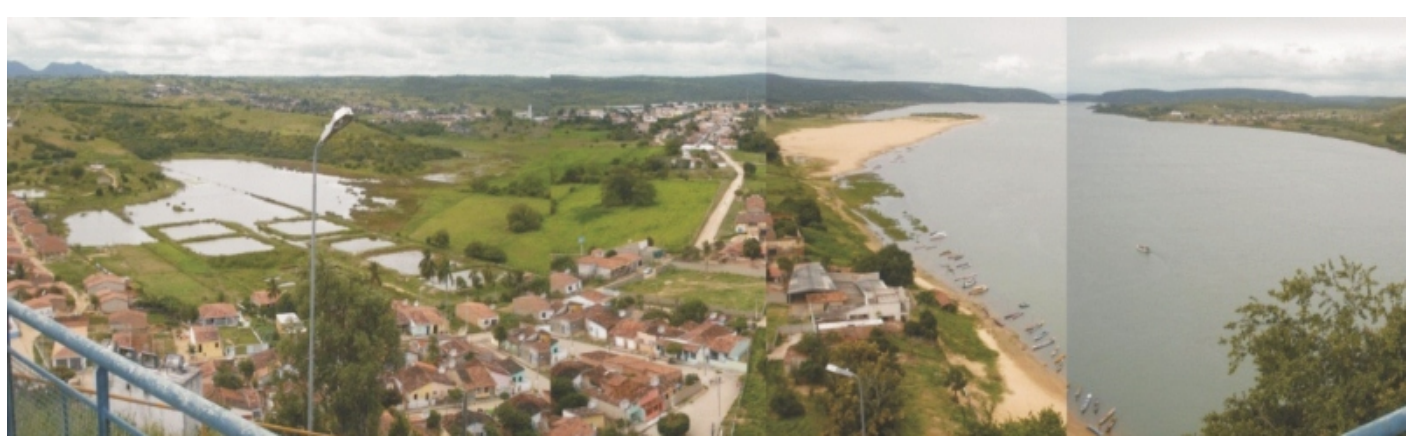

Figura 10 - Imagem registrada durante o mês de agosto (inverno)

Fonte: foto do autor tirada em 2008

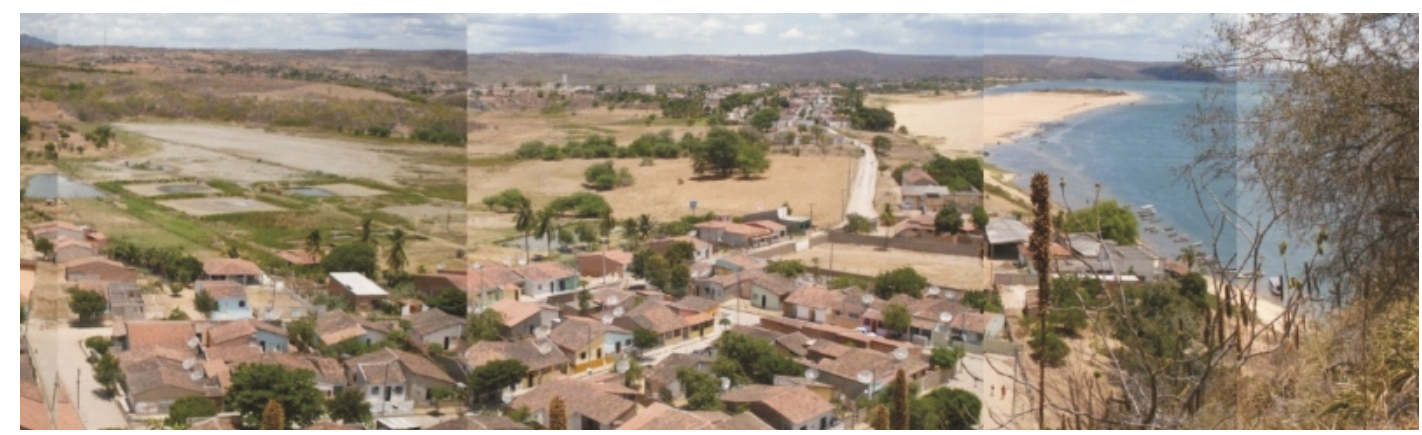

Figura 11 - Imagem registrada durante o mês de janeiro (verão)

Fonte: foto do autor tirada em 2009.

Como mostram os dados acima apresentados, pode-se considerar que a cidade de Pão de Açúcar apresenta características que se assemelham bastante às encontradas em Petrolina. Não obstante, a cidade alagoana pode apresentar uma variação sazonal mais importante, assinalando estações com características particulares:

(a) uma notadamente quente e seca (durante o período de verão), com temperaturas bastante elevadas e umidade relativa baixa; e (b) outra quente e úmida (no período de inverno), com temperaturas mais amenas e elevada umidade relativa do ar.

Essa constatação é de fundamental importância para o conhecimento e a integração das estratégias bioclimáticas mais adequadas para o projeto de arquitetura na cidade.

Duas situações foram registradas a partir de um mesmo ponto da cidade durante as duas estações (Figuras 10 e 11), ilustrando o impacto da variação 
nas condições climáticas na paisagem natural da cidade.

O resultado indica que, para ampliar a zona de conforto (onde se encontram apenas $39,4 \%$ das horas de um ano típico), são recomendadas as estratégias de ventilação natural $(37,5 \%)$ e de ventilação combinada com as estratégias que envolvem alta inércia da envoltória e resfriamento evaporativo (18\%); e alta inércia com resfriamento evaporativo (1,32\%). Durante 1,3\% do ano, faz-se necessário o uso de ar-condicionado (Figura 12).
É possível verificar, como mostra a Figura 13, que, ao existirem duas situações distintas, em função da oscilação da umidade relativa do ar ao longo do ano, a estratégia de ventilação aparece indicada para mais de $70 \%$ no período de maio, cerca de $60 \%$ para junho e julho, e de $45 \%$ para agosto. Entretanto, a partir de setembro, esta é substituída por estratégias de um clima que passa a ser mais seco, com valores de temperatura do ar mais elevados. Nesse período, recomenda-se o uso da alta inércia associado ao resfriamento evaporativo.

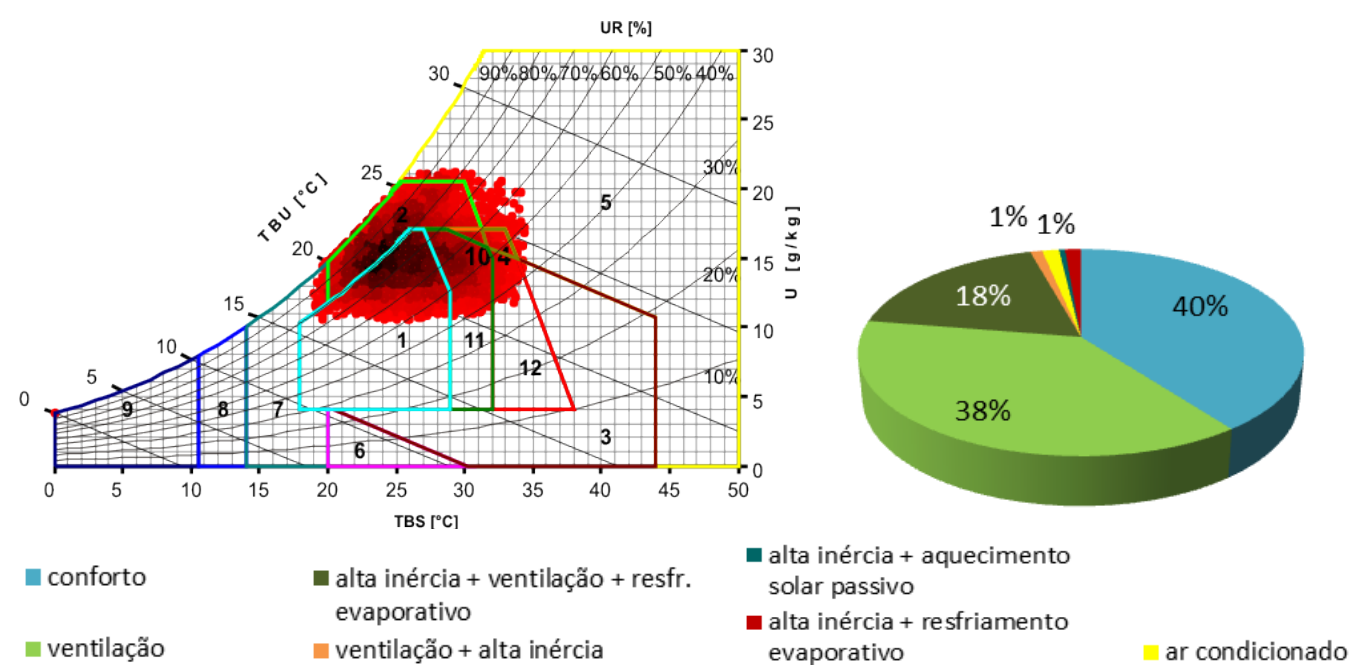

Figura 12 - Carta bioclimática e percentuais das principais estratégias para o município de Pão de Açúcar

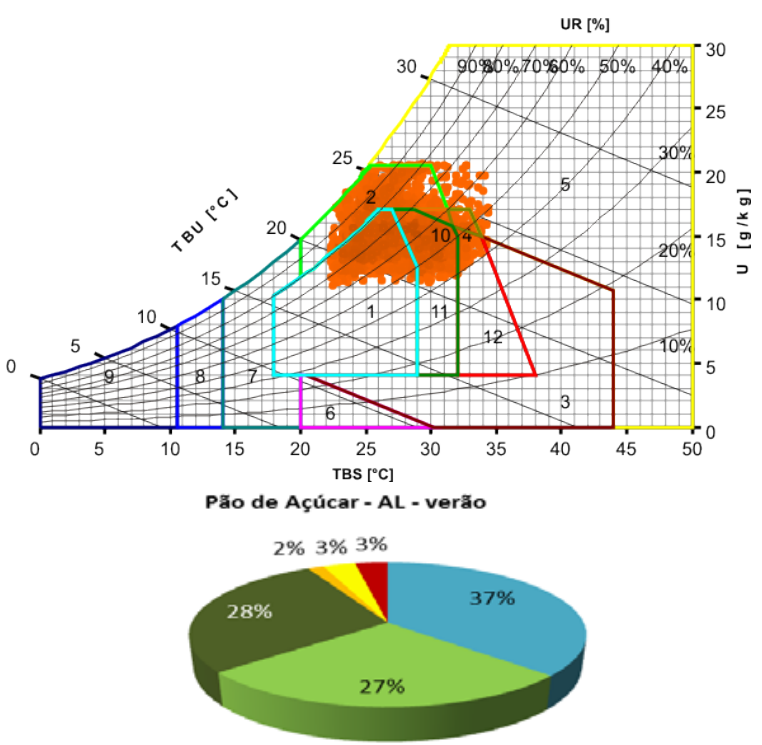

anforto

घventilação
U alta inércia + ventilação + resfr. evaporativo

অ ventilação + alta inércia

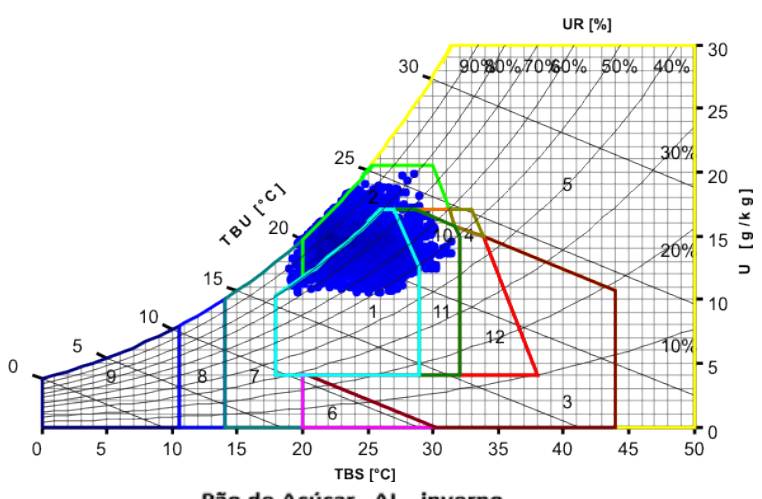

Pão de Açúcar - AL - inverno

$5 \% 2 \%$

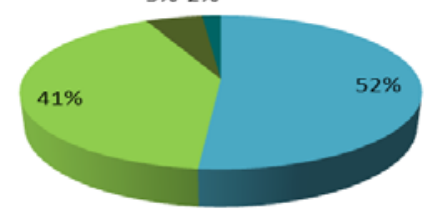

- alta inércia + aquecimento solar

passivo

- alta inércia + resfriamento

evaporativo ar condicionado

Figura 13 - Estratégias bioclimáticas por estação para o município de Pão de Açúcar

70 Martins, T. A. de L.; Bittencourt, L. S.; Krause, C. M. de L. B. 


\section{Síntese e análise comparativa}

Para melhor identificar as características climáticas das cidades analisadas e, assim, poder compará-las às características de Pão de Açúcar, a Tabela 2 apresenta as médias mensais da temperatura do ar e da umidade relativa para as três cidades. Os dados referem-se às normais climatológicas (caso de Maceió e Petrolina). Para Pão de Açúcar, só foram disponibilizados pelo INMET os dados referentes a uma série de 10 anos (1997-2007).

Uma síntese das principais variáveis meteorológicas que as caracterizam, tais como oscilações térmicas sazonal e anual, precipitação e umidade relativa do ar, são apresentadas na Tabela 3.

Como pôde ser observado, o clima da cidade de Pão de Açúcar apresenta características e estratégias bioclimáticas mais próximas das atribuídas à outra cidade sertaneja, Petrolina. Ambas apresentam como recomendação para seus microclimas o uso da alta inércia associado ao resfriamento evaporativo, sugerindo que Pão de Açúcar deveria integrar a ZB-7. No entanto, Pão de Açúcar também possui $40 \%$ de seu ano típico, quando o conjunto de estratégias são os mesmos que os apresentados para todo o ano na capital alagoana. Essa condição pode ser justificada pela variação da precipitação e pela localização da cidade, às margens do rio São Francisco, cujo volume d'água pode acarretar acréscimos importantes na umidade relativa no período de inverno, quando a temperatura diminui e a precipitação aumenta. A análise dos diversos meses do ano mostrou que o clima local apresenta, portanto, características híbridas, variando do quente e úmido (período chuvoso) ao quente e seco (até 8 meses de estiagem), dependendo da época do ano, sugerindo a existência de uma zona de transição entre a ZB-7 e a ZB-8.

\section{Avaliação do desempenho térmico de edifícios construídos de acordo com as recomendações da NBR 15220-3}

Ao passar da classificação climática à proposição de diretrizes construtivas, a NBR 15220-3 (ABNT, 2005) estabelece valores para um conjunto de parâmetros que definem o desempenho térmico recomendado para edificações quando implantadas em cada zona bioclimática.

Tabela 2 - Dados das médias mensais para os climas estudados

\begin{tabular}{|c|c|c|c|c|c|c|c|c|c|c|c|c|}
\hline \multirow[b]{2}{*}{ MÊS } & \multicolumn{4}{|c|}{ Petrolina (ZB-7) } & \multicolumn{4}{|c|}{ Pão de Açúcar (ZB-8) } & \multicolumn{4}{|c|}{ Maceió (ZB-8) } \\
\hline & $\begin{array}{c}\text { TEMP. } \\
\text { MÁX } \\
\left({ }^{\circ} \mathrm{C}\right) \\
\end{array}$ & $\begin{array}{c}\text { TEMP. } \\
\text { MÉD. } \\
\left({ }^{\circ} \mathrm{C}\right) \\
\end{array}$ & $\begin{array}{c}\text { TEMP. } \\
\text { MÍN } \\
\left({ }^{\circ} \mathrm{C}\right) \\
\end{array}$ & $\begin{array}{l}\text { U.R. } \\
\text { (\%) }\end{array}$ & $\begin{array}{c}\text { TEMP. } \\
\text { MÁX } \\
\left({ }^{\circ} \mathbf{C}\right)\end{array}$ & $\begin{array}{c}\text { TEMP. } \\
\text { MÉD. } \\
\left({ }^{\circ} \mathrm{C}\right)\end{array}$ & $\begin{array}{c}\text { TEMP. } \\
\text { MÍN } \\
\left({ }^{\circ} \mathrm{C}\right) \\
\end{array}$ & $\begin{array}{l}\text { U.R. } \\
\text { (\%) }\end{array}$ & $\begin{array}{c}\text { TEMP. } \\
\text { MÁX } \\
\left({ }^{\circ} \mathbf{C}\right) \\
\end{array}$ & $\begin{array}{c}\text { TEMP. } \\
\text { MÉD. } \\
\left({ }^{\circ} \mathrm{C}\right) \\
\end{array}$ & $\begin{array}{c}\text { TEMP. } \\
\text { MÍN } \\
\left({ }^{\circ} \mathrm{C}\right) \\
\end{array}$ & $\begin{array}{l}\text { U.R. } \\
\text { (\%) }\end{array}$ \\
\hline $\mathbf{J}$ & 29,8 & 26,9 & 22,3 & 58 & 36 & 30 & 24 & 60 & 30,2 & 26,2 & 22,4 & 75,4 \\
\hline $\mathbf{F}$ & 31,5 & 27 & 22,3 & 63 & 36,1 & 30 & 24 & 64 & 30,4 & 26,3 & 22,6 & 76,6 \\
\hline $\mathbf{M}$ & 32,4 & 26,6 & 22,2 & 67 & 35,7 & 29,9 & 24,1 & 59 & 30,2 & 25,3 & 22,7 & 78,3 \\
\hline A & 31,3 & 25,8 & 22 & 70 & 34,6 & 29,1 & 23,6 & 66 & 29,6 & 25,9 & 22,5 & 81,5 \\
\hline $\mathbf{M}$ & 30,9 & 25,4 & 21,1 & 64 & 31,9 & 27,3 & 22,7 & 78 & 28,5 & 25,1 & 22 & 82,6 \\
\hline $\mathbf{J}$ & 29,7 & 24,5 & 20,2 & 61 & 29,5 & 25,5 & 21,5 & 81 & 27,6 & 24,3 & 21,3 & 79,6 \\
\hline $\mathbf{J}$ & 31,3 & 24,7 & 19,5 & 60 & 29,3 & 25 & 20,7 & 81 & 27 & 23,7 & 20,5 & 82,1 \\
\hline A & 30,8 & 24,8 & 19,7 & 53 & 30,2 & 25,3 & 20,4 & 77 & 27,1 & 23,5 & 20,2 & 79,5 \\
\hline$S$ & 32,5 & 26,2 & 20,7 & 48 & 32,4 & 26,6 & 20,9 & 69 & 27,8 & 23,9 & 20,7 & 77,2 \\
\hline $\mathbf{O}$ & 33,8 & 27,8 & 22,1 & 48 & 34,7 & 28,4 & 22,1 & 62 & 29 & 24,1 & 21,2 & 76 \\
\hline $\mathbf{N}$ & 34 & 28,2 & 22,9 & 50 & 36,4 & 29,8 & 23,2 & 56 & 29,9 & 24,4 & 21,6 & 74,7 \\
\hline D & 33,1 & 27,1 & 22,5 & 54 & 36,5 & 30,1 & 23,8 & 55 & 30 & 24,8 & 22 & 75,8 \\
\hline
\end{tabular}

Tabela 3 - Síntese das variáveis analisadas para as cidades examinadas

\begin{tabular}{l|c|c|c}
\hline \multirow{2}{*}{ VARIÁVEIS CLIMÁTICAS } & \multicolumn{3}{|c}{ CIDADES } \\
\cline { 2 - 4 } & Petrolina - PE & Pão de Açúcar & Maceió \\
\hline Temperatura do ar $\left({ }^{\circ} \mathrm{C}\right)(\mathrm{em}$ médias $)$ & 22,5 a 31,8 & 23,0 a 34,6 & 22 a 28,9 \\
\hline Amplitude Térmica Sazonal $\left({ }^{\circ} \mathrm{C}\right)$ & 4,6 & 8,1 & 3,8 \\
\hline Amplitude Térmica Diária $\left({ }^{\circ} \mathrm{C}\right)$ & 12,3 & $\mathbf{1 3 , 4}$ & 10,2 \\
\hline Precipitação anual $(\mathrm{mm})$ & 609,8 & 534 & $2.167,70$ \\
\hline Umidade Relativa do ar $(\%)$ & 50 a 68 & 53,6 a 85 & 72,7 a 83,1 \\
\hline
\end{tabular}


Para complementar a análise comparativa entre os três climas abordados, foram realizadas simulações computacionais com a finalidade de conhecer o desempenho térmico de uma edificação padrão, obedecendo às recomendações propostas pela ABNT para ZB-7 e ZB-8. Os valores da temperatura do ar interno, para dias típicos de verão e de inverno ${ }^{3}$, foram comparados aos limites superior e inferior da zona de conforto, conforme equação apresentada anteriormente. Abaixo são ilustrados graficamente os resultados para a cidade de Pão de Açúcar (Figuras 14 e 15). Para Petrolina e Maceió, os dados são apresentados na Figura 16, a fim de compará-los aos de Pão de Açúcar.
Ao comparar os resultados ilustrados nas duas figuras acima, observa-se o papel fundamental desempenhado pela massa térmica na habitação de referência da ZB-7. Esta, ao proporcionar atraso e amortecimento térmico importante do pico de calor do dia, permitiu uma ampla redução na demanda de graus-hora de resfriamento (GHR). A habitação de referência ZB-7 apresentou, portanto, desempenho térmico mais apropriado para o clima de Pão de Açúcar quando comparado ao desempenho da habitação de referência da ZB-8, notadamente no período de verão (Figura 16).

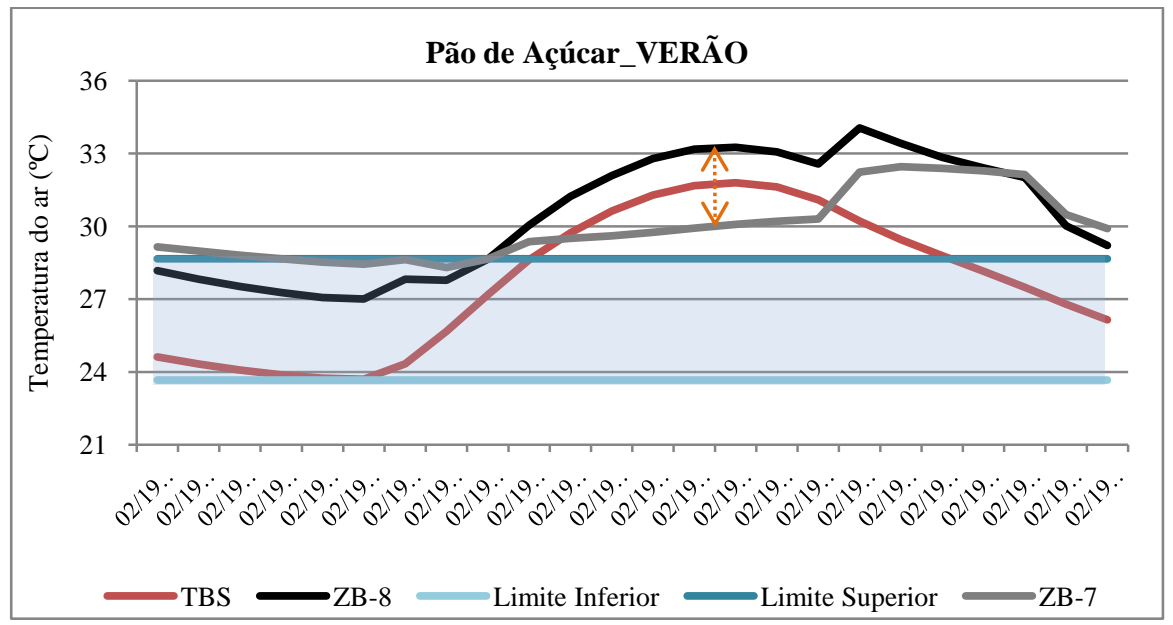

Figura 14 - Dados horários de temperatura para um dia típico de verão na habitação de referência ZB-7 e ZB-8 em Pão de Açúcar

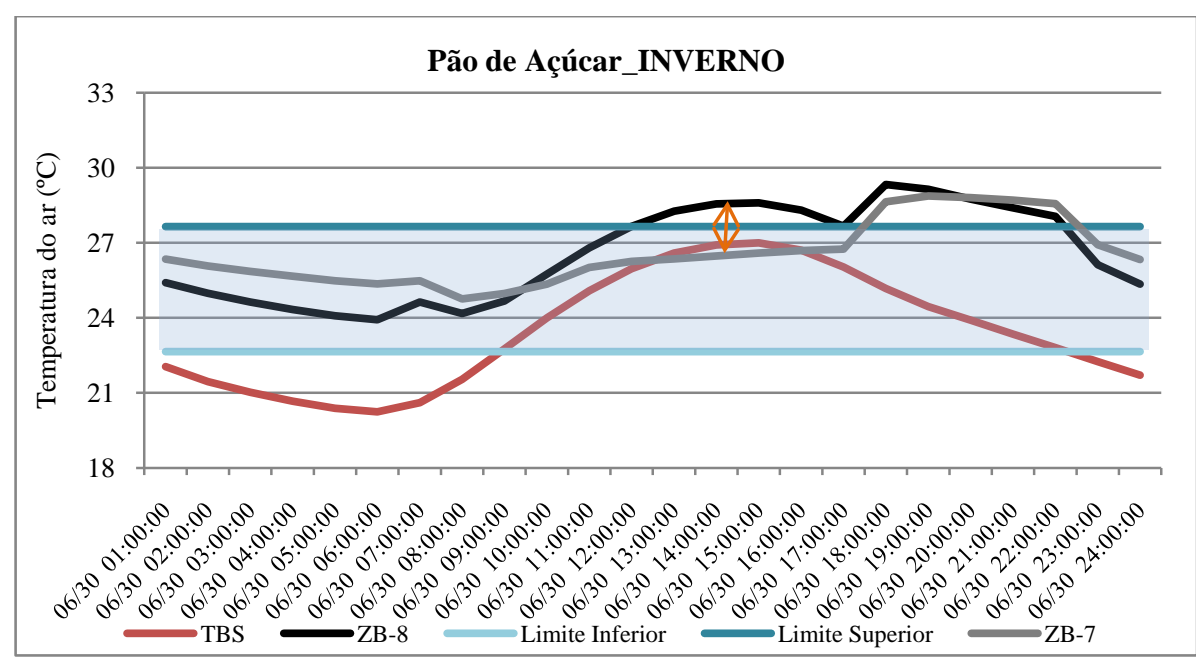

Figura 15 - Dados horários de um dia típico de inverno para temperatura na habitação de referência da ZB-7 e ZB-8 em Pão de Açúcar

\footnotetext{
${ }^{3}$ O dia típico de verão e de inverno foi calculado conforme metodologia de Sattler (1989), descrita por Goulart (1993). Os dias típicos de projeto de verão e inverno para cada cidade foram os seguintes: Petrolina, 15 de fevereiro e 30 de junho; Maceió, 16 de fevereiro e 24 de junho; e Pão de Açúcar, 19 de fevereiro e 30 de junho.
}

72 Martins, T. A. de L.; Bittencourt, L. S.; Krause, C. M. de L. B. 


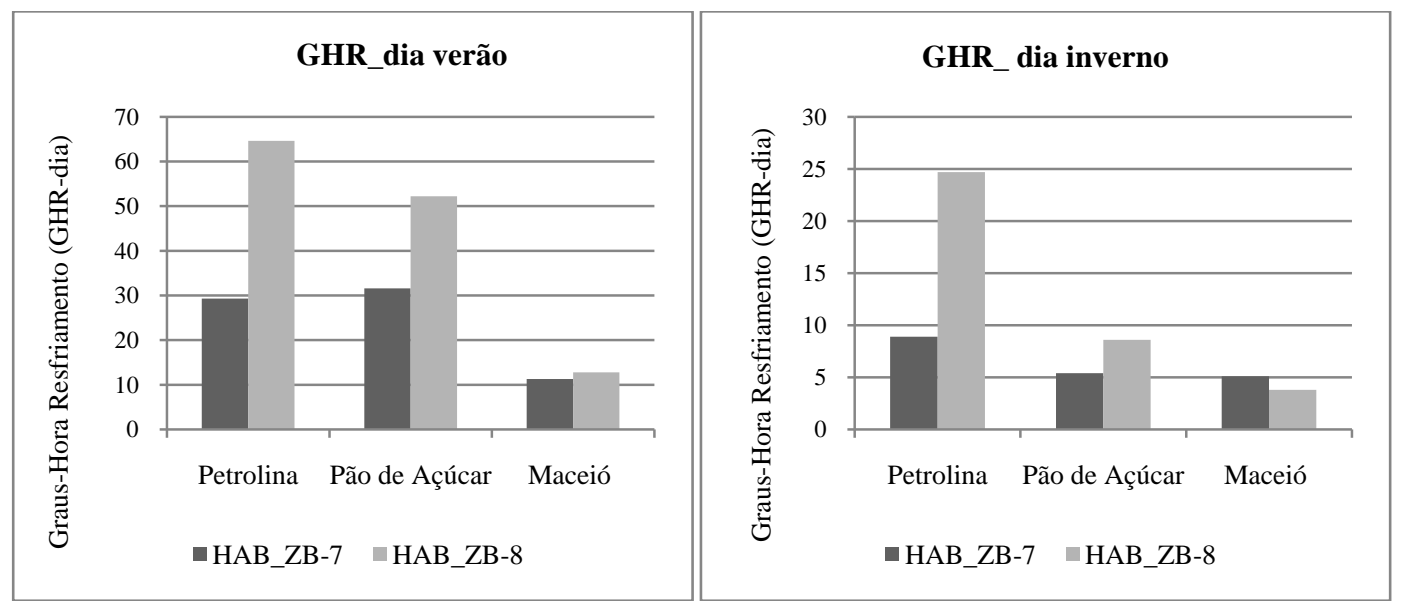

Figura 16 -Graus-hora resfriamento para os modelos de habitação ajustados para ZB-7 e ZB-8 para as três cidades consideradas

Ao comparar os dados por estação para as três cidades, verificou-se, em geral, uma demanda por GHR muito mais importante para as duas cidades do semiárido. A habitação de referência projetada para a ZB-7 apresenta, notadamente, um desempenho térmico mais apropriado ao clima semiárido da cidade de Petrolina (29,3 GHR) e também de Pão de Açúcar (31,6 GHR), quando comparado ao desempenho da mesma habitação ajustada às diretrizes da ZB-8 (64,6 GHR e 52,2 GHR respectivamente) (Figura 16). Já para Maceió, o desempenho térmico durante o dia de inverno é superior para habitação ZB-8 (3,8 GHR) quando comparado a habitação ZB-7 (5,1 GHR).

Os resultados das simulações sugerem, portanto, que as diretrizes construtivas propostas pelo zoneamento bioclimático da NBR 15220-3 (ABNT, 2005) para a cidade de Pão de Açúcar são inadequadas.

\section{Conclusões}

Foram realizadas análises climáticas comparativas e simulações de desempenho térmico de edificação modelada a partir das diretrizes recomendadas pela NBR 15220-3 (ABNT, 2005) para cidade situada no semiárido alagoano, com o objetivo de examinar sua aplicabilidade para essa região. A partir dos resultados obtidos, alguns apontamentos conclusivos podem ser discutidos.

A cidade de Pão de Açúcar - e, possivelmente, outras cidades da mesma mesorregião do semiárido alagoano - apresenta características climáticas que se assemelham mais às das cidades classificadas na ZB-7 do que na ZB-8, onde se encontra atualmente classificada. Porém, essas cidades podem, ainda, apresentar características que também se assemelham, durante quatro meses do ano, ao clima quente e úmido. Tal constatação sugere a existência de uma zona híbrida, de transição entre as regiões quentes e secas e as quentes e úmidas. Conjectura-se, portanto, a necessidade de criarem-se subzonas, ou zonas de transição, de modo a contemplar as variações climáticas existentes. Considera-se, ainda, a possibilidade de estabelecer-se um zoneamento sazonal, de forma a permitir a visualização de estratégias e diretrizes por estação climática (verão e inverno).

As características de uma zona de transição, entretanto, demandam edificações com características diferenciadas, que possam responder de forma eficiente às duas estações distintas. O emprego de componentes híbridos para envoltórias pode apresentar-se como uma solução desejável para responder a essas variações. Um vasto leque de estudos tem sido recentemente realizado nesse sentido, a exemplo de pesquisa sobre materiais de mudança de fase. Esses materiais permitem a obtenção de alta inércia térmica em estruturas leves, podendo ainda ser removidas durante os meses de oscilação térmica reduzida (e.g. incorporação de microcápsulas de materiais de mudança de fase em camadas de revestimento de materiais de construção convencionais). No entanto, tais soluções necessitam de estudos mais aprofundados, de modo a verificar viabilidade e eficiência para o contexto em questão. Não sendo o escopo principal deste artigo, sugere-se, assim, para futuros trabalhos, estudos de otimização energética para avaliação de diferentes composições de envoltória, com vistas a atender, eficientemente, às características de um clima híbrido, como o encontrado em Pão de Açúcar.

Além disso, diante das dificuldades enfrentadas em função da carência de estações meteorológicas automáticas e disponibilidades de dados históricos 
confiáveis para a maior parte do país, salienta-se que discrepâncias possam existir entre séries históricas recentemente publicadas e as normais climatológicas utilizadas pela norma na classificação bioclimática das cidades brasileiras.

Conclui-se, por fim, pela necessidade de aperfeiçoamento nos critérios da classificação dos municípios situados no semiárido alagoano, bem como pela possível criação de zonas bioclimáticas compostas que contemplem diretrizes híbridas de projeto mais adequadas para a combinação de fatores climáticos regionais.

\section{Referências bibliográficas}
AMERICAN SOCIETY OF HEATING, REFRIGERATING AND AIR-CONDITIONING ENGINEERS. ASHRAE Handbook:
fundamentals. Atlanta, 1985.

\begin{abstract}
AMERICAN SOCIETY OF HEATING, REFRIGERATING AND AIR-CONDITIONING ENGINEERS. Standard 55: thermal environmental conditions for human occupancy. Atlanta, 2004.
\end{abstract}

\section{ASSOCIAÇÃO BRASILEIRA DE NORMAS TÉCNICAS. NBR 15220-3: desempenho térmico de edificações: parte 3: zoneamento bioclimático brasileiro e diretrizes construtivas para habitações de interesse social. Rio de Janeiro, 2005.}

BASTOS, L. E. G.; KRAUSE C. B.; BECK, L. Estratégias de Ventilação Natural em Edificações de Interesse Social e a Norma ABNT 15.220: zoneamento bioclimático x potencial eólico brasileiro. In: ENCONTRO NACIONAL DE CONFORTO NO AMBIENTE CONSTRUÍDO, 9., Ouro Preto, 2007. Anais... São Paulo: ANTAC, 2007, p. 172-180.

BRASIL. Ministério da Agricultura e Reforma Agrária. Normais Climatológicas 1961-1990. Brasília: DNMET, 1992. 84 p.

DE DEAR, R.; BRAGER, G. S. Thermal Comfort in Naturally Ventilated Buildings: revisions to ASRHAE Standard 55. Energy and Buildings. v. 34, n. 6, p. 549-561, jul. 2002.

GIVONI, B. Comfort Climate Analysis and Building Design Guidelines. Energy and Buildings, v.18, n.1, p. 11-23, 1992.

GU, L. Airflow Network Modeling in EnergyPlus. In: BUILDING SIMULATION, 10., Beijing, 2007. Proceedings... Beijing: IBPSA, 2007.
GOULART, S. V. G. Dados Climáticos para Avaliação de Desempenho Térmico de Edificações em Florianópolis. Florianópolis, 1993. Dissertação (Mestrado em Engenharia Civil) - Programa de Pós-graduação em Engenharia Civil, Universidade Federal de Santa Catarina, Florianópolis, 1993.

INSTITUTO BRASILEIRO DE GEOGRAFIA E ESTATÍSTICA. Mapa de Climas do Brasil: escala 1:5.000.000. Disponível em:

$<\mathrm{ftp}$ :/geoftp.ibge.gov.br/mapas/tematicos/mapas_ murais/clima.pdf>. Acesso em: 01 nov. 2011.

INSTITUTO BRASILEIRO DE GEOGRAFIA E ESTATÍSTICA. Pesquisa Nacional por Amostra de Domicílios: síntese de indicadores 2001. Rio de Janeiro: IBGE, 2002. 205 p.

INSTITUTO NACIONAL DE

METEOROLOGIA. Dados Horários:

temperaturas, umidade relativa, vento e precipitação das estações meteorológicas de Pão de Açúcar. 2008. 1 CD-ROM.

MARCONI, M. A.; LAKATOS, E. M. Metodologia Científica. 3. ed. rev. amp. São Paulo: Atlas, 2000.

MADEIRA, A. Q. Zoneamento Bioclimático do Estado do Paraná. Dissertação (Mestrado em Engenharia Civil) - Pós-graduação em Engenharia Civil, Universidade Federal de Santa Catarina, Florianópolis, 1999.

MATOS, M. Simulação Computacional do Desempenho Térmico de Residências Em Florianópolis Utilizando a Ventilação Natural. Florianópolis, 2007. Dissertação (Mestrado em Engenharia Civil) - Programa de Pós-graduação em Engenharia Civil, Universidade Federal de Santa Catarina, Florianópolis, 2007.

NIMER, E. Climatologia do Brasil. Rio de Janeiro: FIBGE, 1979.

PEREIRA, I.; ASSIS, E. S. Discussão da Classificação Bioclimática de Belo Horizonte Proposta Pelo Projeto de Norma de Desempenho Térmico de Edificações. In: ENCONTRO NACIONAL DE CONFORTO NO AMBIENTE CONSTRUÍDO, 8., Maceió, 2005. Anais... São Paulo: ANTAC/UFAL, 2005a. p. 1490-1498.

PEREIRA, I.; ASSIS, E. S. Discussão das Estratégias Propostas Pelo Projeto de Norma de Desempenho Térmico de Edificações através de Estudo de Caso. In: ENCONTRO NACIONAL DE CONFORTO NO AMBIENTE CONSTRUÍDO, 8., 2005, Maceió. Anais... São Paulo: ANTAC/UFAL, 2005b. p. 1480-1489. 
PROGRAMA NACIONAL DE CONSERVAÇÃO DE ENERGIA ELÉTRICA. Canal do consumidor: consumo de eletrodomésticos. Disponível em:

$<$ http://www.eletrobras.gov.br/procel $>$. Acesso em: 11 nov. 2011.

REMUND, J.; KUNZ, S.; SCHILTER, C. Handbook of METEONORM Version 6.0, Part II: theory. Meteotest, Fabrikstrasse 14, 3012 Bern, Switzerland, 2007.

ROCHA, A. P; ASSIS, E. S.; GONÇALVES, W. B. Zoneamento Bioclimático do Estado de Minas Gerais: aperfeiçoamento dos resultados. In: ENCONTRO NACIONAL DE CONFORTO NO AMBIENTE CONSTRUÍDO, 10., Natal, 2009. Anais... Natal: ANTAC/UFRN, 2009. p. 800-809.

ROMERO, M. A. B. Princípios Bioclimáticos Para o Desenho Urbano. São Paulo: Projeto, 1988.

RORIZ, M. Um Método Para a Interpolação de Dados Climáticos. In: ENCONTRO NACIONAL DE CONFORTO NO AMBIENTE CONSTRUÍDO, 5., Fortaleza, 1999. Anais... São Paulo: ANTAC, 1999.

RORIZ, M.; LAMBERTS, R; GHISI, E. Avaliação de Desempenho Térmico de Sistemas Construtivos: projeto inovação tecnológica. Florianópolis; São Paulo: UFSC; UFSCar, 1998. (Convênio ITQC/SEPURB/CEF).

RORIZ, M.; GHISI, E.; LAMBERTS, R. Um Zoneamento Bioclimático Para a Arquitetura no Brasil. In: JORNADA SOBRE CLIMA E APLICAÇÃO NA COMUNIDADE DE PAÍSES DE LÍNGUA OFICIAL PORTUGUESA, 2. Maceió, AL, 2001. Anais... Maceió: UFAL, 2001. p. 1-7.
SATTLER, M. A. Dias Climáticos Típicos para o Projeto Térmico de Edificações em Porto Alegre. Porto Alegre: CIENTEC, 1989.

SILVA, A. C. S. B. Zoneamento Bioclimático Brasileiro Para Fins de Edificações. Porto Alegre, 1994. Dissertação (Mestrado em Engenharia Civil) - Departamento de Engenharia Civil, Universidade Federal do Rio Grande do Sul, Porto Alegre, 1994.

SISTEMA DE INFORMAÇÕES DE POSSES DE ELETRODOMÉSTICOS E HÁBITOS DE CONSUMO. Núcleo de Estatística Computacional. Rio de Janeiro: Pontifícia Universidade Católica do Rio de Janeiro, 1999.

TAVARES, S. F. Metodologia Para Análise do Ciclo de Vida Energético de Edificações Residenciais Brasileiras. Tese (Doutorado em Engenharia civil) - Programa de Pós-Graduação em Engenharia Civil, Universidade Federal de Santa Catarina, Florianopolis, 2006.

WALTON, G. N. Thermal Analysis Research Program (TARP) Reference Manual.

Washington: US Department of Commerce, National Bureau of Standards, Building Physics Division, 1983.

ZÁRATE, L. E. et al. Estimativa de Dados Climáticos Utilizando Redes Neurais Artificiais Para Fins de Zoneamento Bioclimático do Estado de Minas Gerais. In: ENCONTRO NACIONAL DE TECNOLOCIA DO AMBIENTE CONSTRUÍDO, 12., Fortaleza, 2008. Anais... São Paulo: ANTAC/UFCE, 2008. 10 p.

\section{Agradecimentos}

Os autores gostariam de agradecer à CAPES, pelo auxílio financeiro concedido ao longo do desenvolvimento da pesquisa.

Revista Ambiente Construído

Associação Nacional de Tecnologia do Ambiente Construído

Av. Osvaldo Aranha, 99 - 3o andar, Centro

Porto Alegre - RS - Brasil CEP 90035-190

Telefone: +55 (51) 3308-4084 Fax: +55 (51) 3308-4054

www. seer. ufrgs. br/ ambienteconstruido

E-mail: ambienteconstruido@ufrgs.br 